\title{
Prospective Electric Power Cooperation among Northeast Asian Countries in the Context of Carbon Tax
}

\author{
S. V. Podkovalnikov*, L. Yu. Chudinova
}

\begin{abstract}
Melentiev Energy Systems Institute of Siberian Branch of Russian Academy of Sciences, Irkutsk, Russia
\end{abstract}
\begin{abstract}
The paper addresses the prospects for power grid formation in Northeast Asia in terms of carbon dioxide emissions. Carbon dioxide tax is implemented as a tool to quantitatively engage environmental issues in the study. A survey of the studies on the prospective NEA power grid has been done. The research employs a methodology and a mathematical model for the optimization of power system expansion and economic dispatching of power plants. Environmentally friendly scenarios of the NEA power grid were built and studied.
\end{abstract}

Index Terms: Northeast Asia, electric power cooperation, interstate electric tie and grid, interconnection, system effects, economic effectiveness.

\section{INTRODUCTION}

Interstate electric power cooperation started as a process of creating interstate electric ties (ISETs) and shaping interstate power grids (ISPGs) at the beginning of the last century with the advent of the first ISETs in Western Europe and North America. Since then, this process has become a global trend covering all regions of the world and continents.

The driving forces of this trend are the benefits to be achieved as a result of electric power cooperation, such as a) reduction in the need for the installed generating capacities due to the time difference in load maxima (both daily and annual) in different countries and regions; b) improvement in the reliability of the interconnected electric power systems (EPSs); c) large-scale integration of renewable (hydraulic, wind, solar, tidal) energy sources in

\footnotetext{
${ }^{*}$ Corresponding author.

E-mail: spodkovalnikov@,isem.irk.ru
}

http://dx.doi.org/10.38028/esr.2020.03.0004

Received April 09, 2020. Revised May 21, 2020.

Accepted June 13, 2020. Available online December 27, 2020.

This is an open access article under a Creative Commons Attribution-NonCommercial 4.0 International License.

(C) 2020 ESI SB RAS and authors. All rights reserved. the interconnected EPSs of different countries; d) expansion of electricity markets and intensification of electricity trade between countries; e) income generation from extended electricity trade within the interstate electricity markets; and others. [1].

The trend has also been persistent in the Asian region, although to a varying extent in different subregions, including Central, South, Southeast, and Northeast Asia (NEA). The power grid of Central Asia was mainly formed as part of the Unified power system of the Soviet Union. Now it is functioning as a separate and independent entity expanding inner and outer ISETs. The Southeast power grid is extensively developing with the support of ASEAN (Association of Southeast Asian Nations) countries getting benefits from electric power cooperation. The countries involved in the South power grid (backed by SAARC - South Asian Association for Regional Cooperation) build ISETs facilitating electricity cooperation within the subregion for mutual benefits. NEA lags behind the process of power cooperation mainly for political reasons. The current electricity exchange in the NEA subregion is insignificant, but the studies prove considerable potential benefits from the ISETs and subregional grid formation [15, and others].

\section{STUDIES OF POTENTIAL NEA POWER SYSTEM INTERCONNECTIONS}

Initially, power system interconnection in NEA was considered and studied as bilateral, maximum, trilateral projects of ISETs connecting EPSs of two or three countries for a joint operation to gain the benefits of systems integration. These are the projects of ISETs 'RussiaDemocratic People's Republic of Korea (DPRK)-Republic of Korea (RoK)', 'Russia-North China', and others [1,6,7, a.o.]. It is worth noting that until recently, none of the studies on the ISETs in NEA has considered the formation of a single Northeast Asian interstate power grid. Currently, the studies have advanced to the level of the interstate power interconnection of the entire NEA subregion. Some of those carried out to date are presented in [3,4,8-14]. The studies discussed in $[3,4,8,13,14]$ are distinguished from 
those noted above by the extensive mathematical modeling and the application of optimization models to shape the prospective NEA-wide power grid. They will concisely be considered below.

Acomprehensive assessment of the system effectiveness of the entire NEA interstate power grid was made in [3]. The study quantitatively investigated the economic viability of power grid interconnections in NEA and renewable energy developments in the Gobi Desert and Eastern Russia. The investigations focused on different Scenarios of the NEA power system interconnection for the target year 2030, including the absence of the interconnection and the Gobitec project. The Scenarios were found to be economically and environmentally feasible. The results show rather modest benefits in lowering the total cost because of the large investments needed to develop the renewables and the transmission lines.

A Scenario with the generation based solely on renewable energy sources (RES) in the NEA grid is studied in [4]. The study states that the existing RES technologies can generate enough energy to cover all electricity demand of NEA for the year 2030 at a lower price compared to non-renewable options. The high voltage direct current (HVDC) transmission infrastructure plays a key role since the established Super Grid enables a significant cost decrease within the renewable resource-based power system. The use of HVDC transmission lines will reduce the employment of energy storage systems and significantly curtail generation capacities.

Our studies presented in $[8,13,14]$ differ from other studies by the following: a) all countries in NEA subregion are considered, b) consumer loads and generating capacities are examined for all nodes (representing EPSs of the countries or their territories) of NEA interstate grid, c) the system benefits resulting from the interstate power grid establishment in NEA are assessed in detail, d) all participating countries share the system benefits. These studies show that the integration of the national power systems of NEA countries makes it possible to obtain substantial system benefits. Ramified bulk power interstate transmission infrastructure is to be developed in the subregion to attain the noted benefits through intensive electricity trading. The findings indicate that all the countries involved receive benefits from joining the interstate power grid in NEA. Thus, the grid is economically feasible for each participating country.

\section{THE GENERALIZED METHODOLOGY}

The study relied on a special optimization mathematical model. It optimizes the expansion of installed generating and transmitting capacities and their economic dispatching within electric power systems and the interconnected grid. Technical features of EPSs are presented in the model in detail as a set of specific constraints and balance equations. The model was presented in $[1,13]$ and elsewhere, which is why it is not described here in detail.
The methodology involves complex optimization studies for the no-ISPG Scenario (Scenario 1) and the ISPG Scenario (Scenario 2) using the above mathematical model. The objective function of the model is the annualized cost for all interconnected power systems, which is minimized for both Scenarios:

$$
Z_{\text {sep }}(X) \rightarrow \min , \quad Z_{\text {inter }}(X) \rightarrow \min ,
$$

where $Z_{\text {sep }}(X)$ is the objective function of the model for Scenario $1 ; Z_{\text {inter }}(X)$ is the objective function of the model for Scenario $2 ; X$ is a vector of the model variables, including actual hourly power and installed capacity of power plants of different types (thermal power plants (TPPs) based on steam turbine, gas turbine, combined cycle, including cogeneration; nuclear power plants; hydroelectric and pumped storage power plants) using different types of organic fuel (coal, gas, oil), transfer capabilities of electric tie lines and hourly power flow via them.

The resulting optimal values of the objective function from expression 1 are compared with each other: $Z_{\text {sep }}(X) \gtrless$ $Z_{\text {inter }}(X)$. If the cost in Scenario 2 is lower than in Scenario 1: $Z_{\text {sep }}(X)>Z_{\text {inter }}(X)$, the ISPG is effective; otherwise, it is not. The economic effect of the power interconnection is defined as the difference in costs (values of the objective function) for Scenarios 1 and 2:

$$
\pm \mathrm{E}=Z_{\text {sep }}(X)-Z_{\text {inter }}(X) .
$$

If the power system interconnection is effective, the effect will be positive, otherwise, it will be negative (i.e., there will be losses due to the formation of the power system interconnection). This effect is composite. It includes the system effects obtained through the ISPG formation, including capacity and fuel-saving effects.

\section{ASSUMPTIONS AND SCENARIOS}

The study presented in the paper is a continuation of our previous investigations $[8,13,14]$. It differs from the previous ones in the following:

a). a new target year was assumed;

b). Northwest China electric power system (EPS) was considered as a new node connected to the node of North-Central-East China EPS and through this node connected to other Chinese and NEA grids;

c). electric power and economic indices for calculations were adjusted according to the new target year, and

d). carbon dioxide (CO2) tax on electricity generation from fossil fuel thermal power plants was taken into account in the environmental Scenarios of the research.

The following Scenarios for the studied NEA power system interconnection were built considering the influencing factors and conditions: 1) without interstate NEA grid; 2) with interstate NEA grid; 3) without interstate NEA grid, with $\mathrm{CO}_{2}$ tax $\left.1 ; 4\right)$ with interstate NEA grid, with $\mathrm{CO}_{2}$ tax $\left.1 ; 5\right)$ without interstate NEA grid, with $\mathrm{CO}_{2}$ $\operatorname{tax} 2 ; 6$ ) with interstate NEA grid, with $\mathrm{CO}_{2} \operatorname{tax} 2$. Tax 1 in 


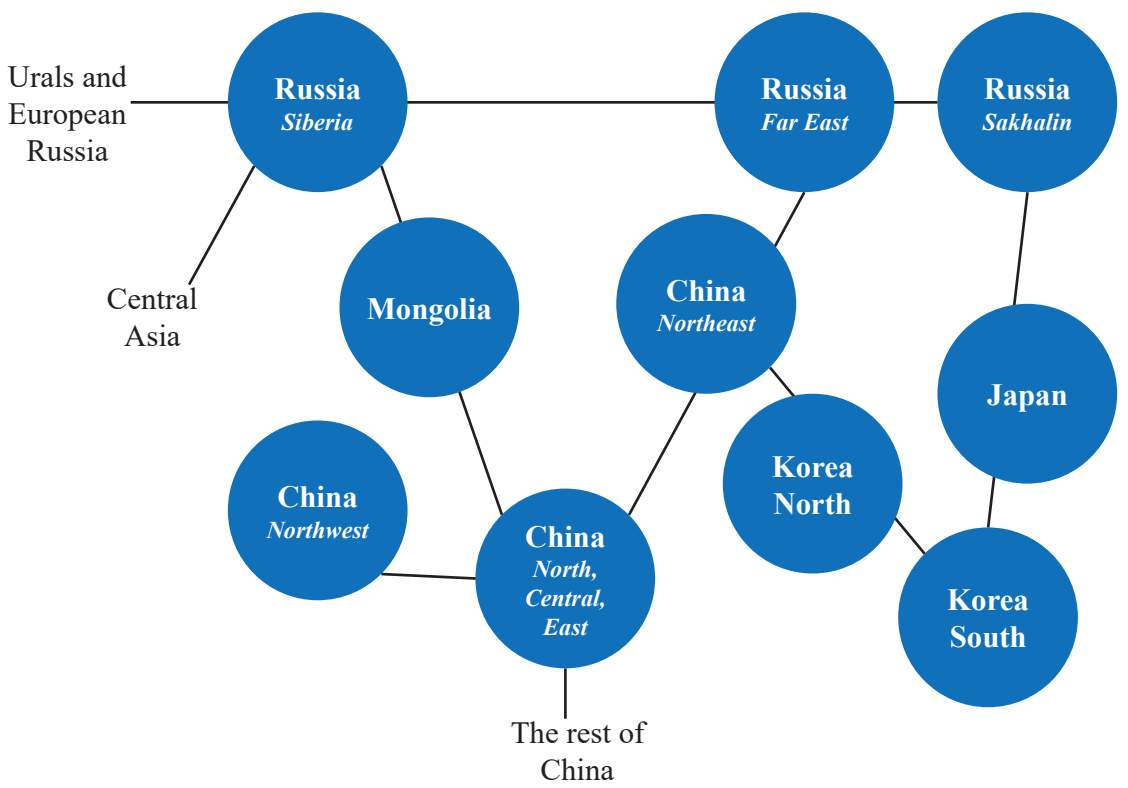

Fig. 1. Diagram of the interstate power grid in NEA.

Scenarios 3 and 4 differs from tax 2 in Scenarios 5 and 6 (see the next Section for detail).

The target year assumed for the study was 2040 .

Figure 1 presents a diagram (a set of nodes standing for national or regional EPSs and electric ties) of the potential interstate power interconnection in NEA, which is represented by ten nodes, including three nodes in the territory of Russia (EPS of Siberia, EPS of the Far East and EPS of Sakhalin), and three more nodes in China (EPS of North-Central-East China, EPS of Northeast China and EPS of Northwest China). EPSs of other countries are represented by one node in the diagram.

\section{INPUT DATA}

Input data for the research were taken from the reports and studies made by international, governmental, and scientific organizations of the considered East Asian countries [14-17, and others]. Prospective demand for electricity in the NEA countries was assumed to grow according to business-as-usual national scenarios [16]. Main economic and some technical input data for the model are presented in Tables 1-3. Table 2 presents fuel costs given in ranges for different power plants located in various territories of a country or having different generating technologies but using the same fuel.

The ISETs to be installed are HVDC $\pm 800 \mathrm{kV}$ transmission lines and submarine cables. The cables are needed to cross the sea straits (between mainland and Japan, mainland and Sakhalin, Sakhalin and Hokkaido). The ISET costs in Table 3 were calculated considering a particular route length, transfer capability, and others.

Wind and solar renewable power facilities are assumed in the study for the target year according to the national power strategies and are not optimized in the model.

Table 1. Capital investment in power plants, usd $/ \mathrm{kw}$.

\begin{tabular}{|c|c|c|c|c|c|c|}
\hline & \multirow[t]{2}{*}{ Hydro } & \multirow[t]{2}{*}{ Pumped storage } & \multicolumn{3}{|c|}{ Thermal } & \multirow[t]{2}{*}{ Nuclear } \\
\hline & & & Coal & Gas & Fuel oil & \\
\hline Russia (Siberia, Far East, Sakhalin) & 3000 & - & 2000 & 1200 & - & 2800 \\
\hline Mongolia & 3200 & 1000 & 1300 & - & - & - \\
\hline China (North, Northeast, Northwest) & 2500 & 1000 & 800 & - & - & 2500 \\
\hline RoK & 2500 & 1200 & 1500 & 850 & 1900 & 2500 \\
\hline DPRK & 2500 & - & 2000 & 1200 & 1500 & - \\
\hline Japan & 6000 & 2400 & 2500 & 1250 & 1900 & 4000 \\
\hline
\end{tabular}

Table 2. Fuel costs, usd/mwh.

\begin{tabular}{|c|c|c|c|c|}
\hline & \multicolumn{3}{|c|}{ Thermal } & \multirow[t]{2}{*}{ Nuclear } \\
\hline & Coal & Gas & Fuel oil & \\
\hline Russia (Siberia, Far East, Sakhalin) & $15-23$ & $16-35$ & - & 5 \\
\hline Mongolia & $22-24$ & - & - & - \\
\hline China (North, Northeast, Northwest) & $22-24$ & 41 & - & 9 \\
\hline RoK & $32-33$ & $69-72$ & 249 & 8 \\
\hline DPRK & 25 & 52 & 110 & - \\
\hline Japan & $32-33$ & $71-73$ & 249 & 9 \\
\hline
\end{tabular}


Table 3. Technical and economic indices of electric ties.

\begin{tabular}{|c|c|c|c|c|c|c|c|c|c|}
\hline Tie lines & 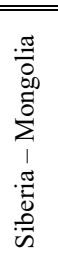 & 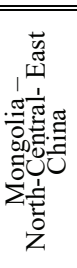 & 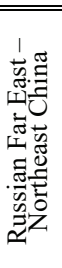 & 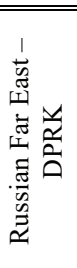 & 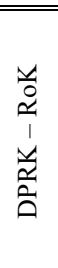 & 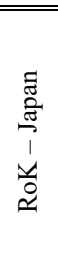 & 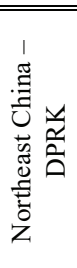 & 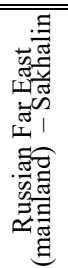 & 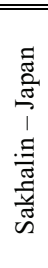 \\
\hline $\begin{array}{lll}\text { Capital } & \text { investment } & \text { in } \\
\text { ISETs } & \text { [USD/kW } & \text { of } \\
\text { transfer capability] } & \end{array}$ & 420 & 260 & 270 & 480 & 180 & 950 & 180 & 550 & 900 \\
\hline Transmission losses [\%] & 5.0 & 5.6 & 4.9 & 7.1 & 1.0 & 3.7 & 1.8 & 3.4 & 4.6 \\
\hline
\end{tabular}

In the context of the expected uncertainty, carbon tax was represented in the study by two options - USD 40 (tax $1)$ and USD $60(\operatorname{tax} 2)$ per ton $[18,19]$.

\section{THE RESULTS AND DISCUSSIONS}

Figure 2 demonstrates the substantial benefits of Scenarios 2, 4, and 6 of the interstate grid in NEA (compared to Scenarios 1, 3, and 5 of separate operation of the national EPSs in NEA). The benefits indicate the feasibility of the interstate power grid in NEA. The estimations of the interstate power grid in NEA show a 60-64 GW reduction in the total number of generating capacities to be added in the NEA countries, with China being the major beneficiary. Annual cost saving is calculated to be USD 17-20 billion. Fuel cost saving is about USD 9-15 billion a year. Japan and RoK gain a greater share of this saving. A significant variation in the fuel benefit by Scenario is due to the consideration of $\mathrm{CO}_{2}$ tax. As seen in Figure 2, the fuel benefit rises with tax growth. The highest fuel benefit (USD 14.9 billion) corresponds to the highest accepted tax value (USD 60/ton of CO2) because the tax was transformed to and included in the fuel cost. The investment benefit, however, decreases with the tax rise, which is due to the replacement of fossil fuel TPPs by capital-intensive nuclear and hydropower plants under the $\mathrm{CO}_{2}$ emission tax imposed.

Figure 3 confirms and clarifies the above statement about the replacement of fossil fuel TPPs by carbon-free and low-carbon generation when $\mathrm{CO} 2$ tax is imposed. The Figure indicates that the considerable decrease in power generation by coal-fired TPPs in Scenario 4 (with the interstate NEA grid and USD 40 tax) versus Scenario 2 is offset by carbon-free generation and gas-fired generation with low-carbon emissions. The tax growth up to USD 60 (Scenario 6) further suppresses the coal-fired TPPs generation, but nuclear and renewable capacities do not

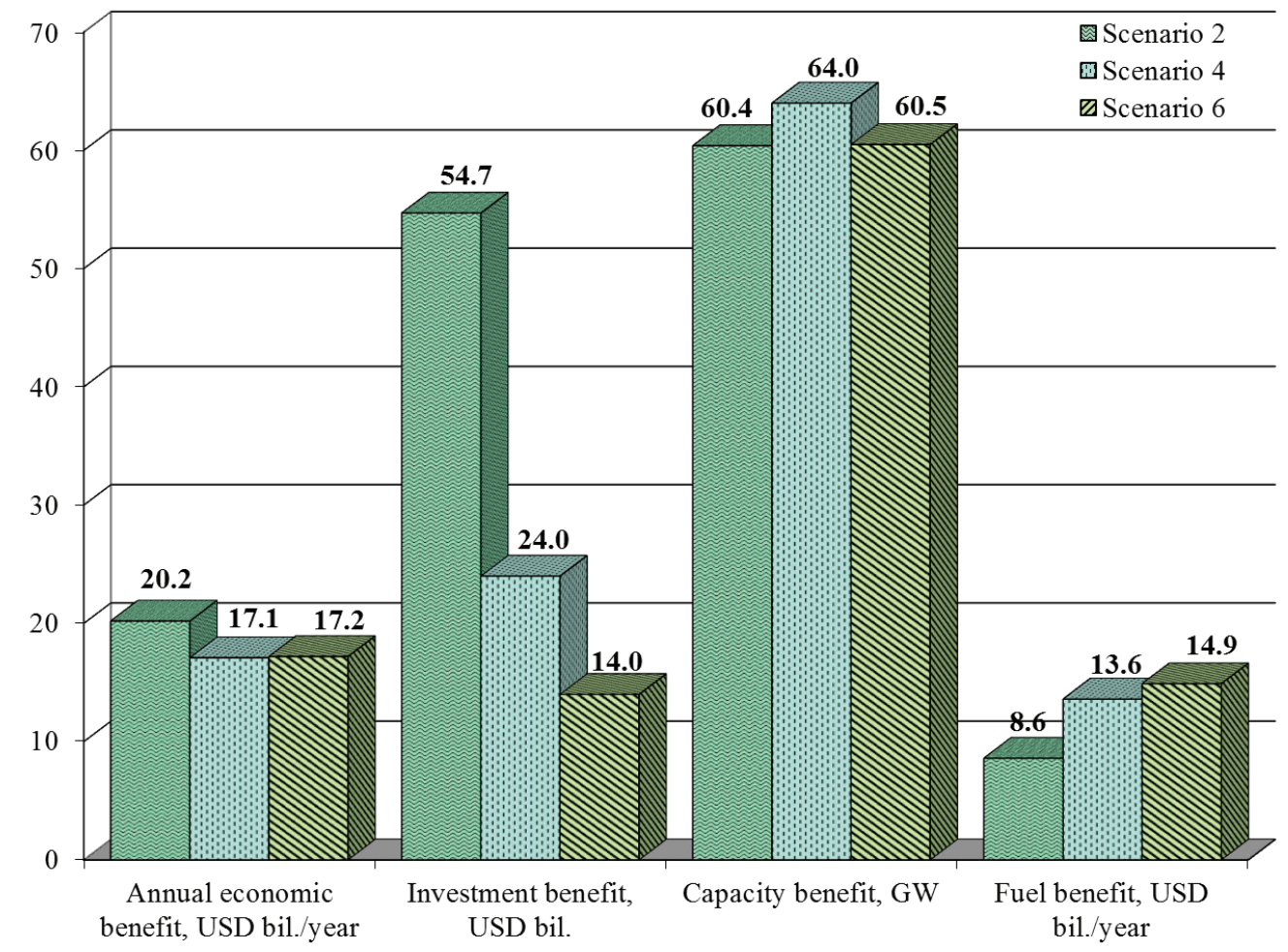

Fig. 2. System benefits of the interstate NEA grid. 


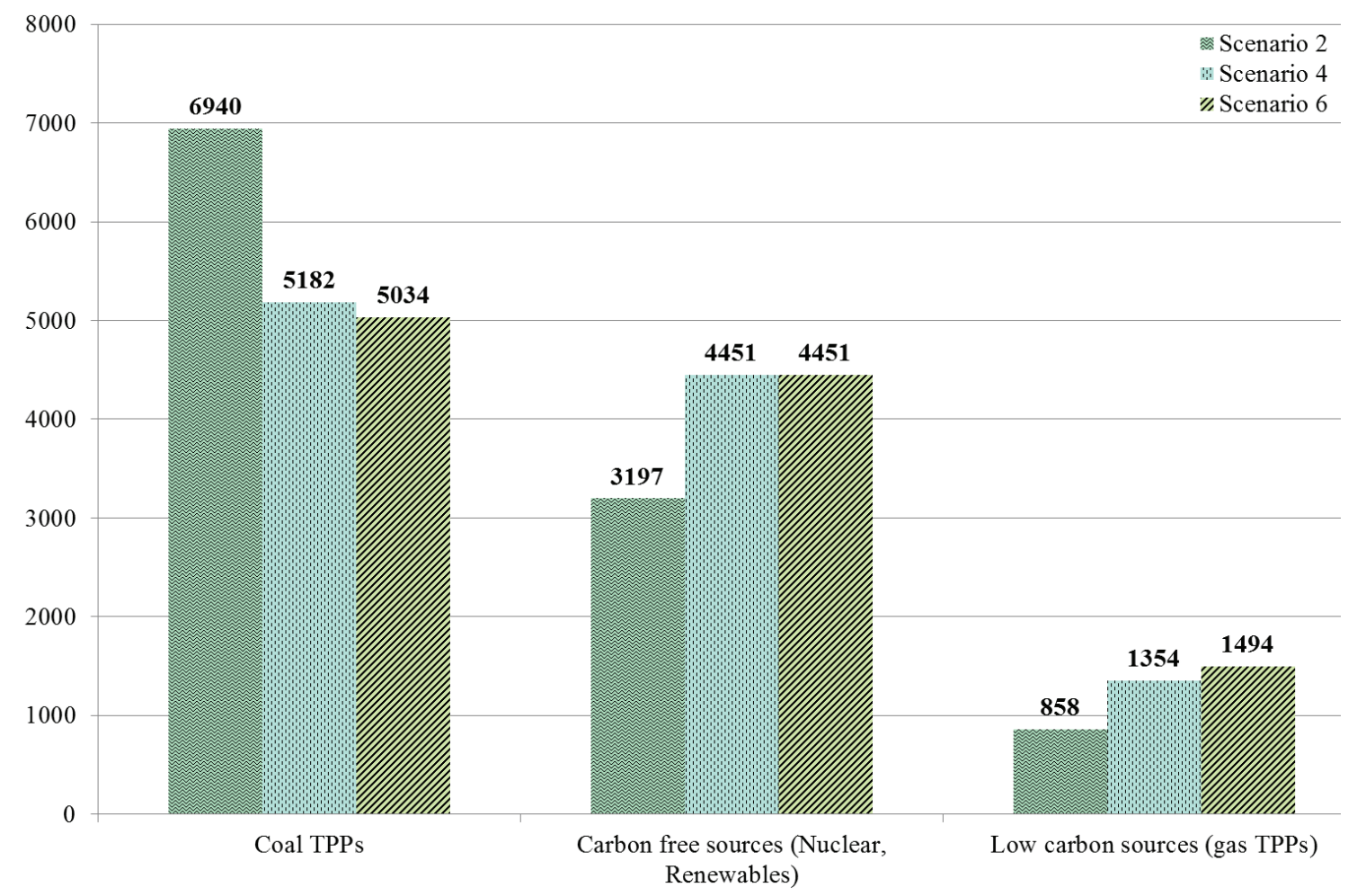

Fig. 3. Power generation by type of power plant [TWh/year].

respond because nuclear installed capacity reaches its expansion limits (constraints) and renewable installed capacity, as was noted, is assumed to be fixed. Instead, low-carbon sources such as gas-fired TPPs appear and increase their power output.

Power generation from coal-fired TPPs in Scenarios with $\mathrm{CO}_{2}$ tax decreases mainly in China (up to about $40 \%$ in Scenario 6) and partly in RoK and Japan. The growth of power generation substitution is mostly provided by nuclear generation from China and partly from RoK and Russia. Following the noted change in the power generation mix, the prospective installed capacity mix and

capacity additions in the potential NEA grid and national EPSs also change. Thus, the coal-fired capacity additions in China in Scenario with the maximum tax are about half of those in Scenario with no $\mathrm{CO}_{2}$ emission tax. Moreover, there is a concurrent six-fold increase in the nuclear capacity additions in this country.

The integration benefits in the NEA grid are accompanied by a considerable electricity exchange among all its participants. The potential power exchange (totally export and import) among NEA countries is estimated at nearly 700 TWh annually in the target year in Scenario 2 with no CO2 emission tax. In Scenario 6, with the maximum tax, power exchange varies insignificantly. Thus, the $\mathrm{CO} 2$ emission tax strongly affects mixes of power generation and capacity additions in contrast to power exchange among NEA countries.

There is a considerable power flow from China across the Korean peninsula to Japan, which is complemented by the flow along the northern route from the Russian Far East. The countries of the Korean peninsula play mainly the role of transmitters. Japan's energy security requirement in terms of the permissible power import is not violated. Russia and China (through Mongolia), and Russia and the countries of the Korean peninsula participate in the mutual power exchanges, thus gaining the system integration benefits from the interstate grid in NEA.

The total transfer capability of ISETs in the NEA interstate grid is maximum for Scenario 2 with no tax, and it is estimated to be about $83 \mathrm{GW}$. Although the transfer capability somewhat declines (by 6\%) in Scenario 6 with the maximum tax, it remains considerable. The most powerful (14-15 GW) electric ties appear between North-Central-East China and Russian Siberia (through Mongolia), Northeast China and DPRK, DPRK and RoK, RoK and Japan.

Development of ISETs between national EPSs in the NEA countries, which have different mixes of generating capacities, daily and yearly load curves and load peaks, and renewable energy sources, results in their close relations and interdependence, and finally shapes the interstate NEA grid.

\section{SUMMARY}

The potential interconnection of power systems in the NEA subregion can be expected to bring about significant benefits for participant countries, including savings of installed capacity, investment, fuel cost, and total annual cost. To gain the benefits, it is necessary to establish a powerful transmission infrastructure in the NEA subregion. 
The introduction of $\mathrm{CO}_{2}$ emission tax in NEA countries can substantially change mixes of installed capacity and power generation in favor of carbon-free and low-carbon electricity sources. However, the imposition of the tax will have little impact on potential electricity exchanges among the NEA countries, although the transfer capabilities of prospective ISETs will somewhat change.

\section{ACKNOWLEDGMENT}

The research was carried out under State Assignment, Project 17.6.2 (reg. no. AAAA-A17-117030310447-3) of the Fundamental Research of Siberian Branch of the Russian Academy of Sciences.

\section{REFERENCES}

[1] L.S. Belyaev, S.V. Podkovalnikov, V.A. Saveliev, L.Yu. Chudinova. Effectiveness of Interstate Electric Ties. Novosibirsk: Nauka, 2008. 239 p. (in Russian).

[2] L.Yu. Chudinova, S.V. Podkovalnikov, V.A. Savel'ev. Prospects of Electric Energy Cooperation between Russia and Northeast Asian Countries. Studies on Russian Economic Development. Vol. 26, no. 4. pp. 403-412. 2015. DOI: 10.1134/s1075700715040085.

[3] T. Otsuki, A.B.M. Isa, R.D. Samuelson. Electric Power Grid Interconnections in Northeast Asia: a Quantitative Analysis of Opportunities and Challenges. Energy Policy. Vol. 89, pp. 311-329, Feb. 2016. DOI: 10. 1016/j.enpol.2015.11.021.

[4] D. Bogdanov, C. Breyer. Northeast Asian Super Grid for 100\% Renewable Energy Supply: Optimal Mix of Energy Technologies for Electricity, Gas and Heat Supply Options. Energy Conversion and Management. Vol. 112, no 15, pp. 176-190, March 2016. DOI: 10.1016/j.enconman.2016.01.019.

[5] Zh. Liu, Global Energy Interconnection. New York: Elsevier, 2015. 396 p.

[6] L.S. Belyaev, L.Yu. Chudinova, O.V. Khamisov, G.F. Kovalev, L.M. Lebedeva, S.V. Podkovalnikov, V.A. Savelyev. Studies of Interstate Electric Ties in Northeast Asia. International Journal of Global Energy Issues. Vol. 17, no 3, pp. 228-249, 2002 DOI: 10.1504/IJGEI.2002.000942.

[7] J.Y. Yoon, D.W. Park, H.Y. Kim. The Pre-feasibility Results of NEAREST between the ROK, the DPRK, and the RF. in Proc. of 6th International Conference Asian Energy Cooperation: Forecast and Realities, Irkutsk, Russia, 2008, pp. 59-67.

[8] S.V. Podkovalnikov, V.A. Saveliev, L.Yu. Chudinova. Study of System Effectiveness of Northeast Asia Power Interconnection. Proc. of the Russian Academy of Sciences. Energy, no 5, pp. 16-32, 2015. (in Russian).

[9] S. Mano, B. Ovgor, Z. Samadov, M. Publik, V. Julch, D. A. Sokolov, J. Yoon. Gobitec and Asian super grid for renewable energies in Northeast Asia. Spotinov print Ltd, 110 p, 2013. Available at: http://www. encharter.org/fileadmin/user_upload/Publication/ Gobites_and_Asian_SuperGrid_2014_ENG.pdf.
[10] Asia International Grid Connection. Study Group. Second Report Summary Information. Japan, Tokyo: Renewable Energy Institute, 36 p. June, 2016. Available at: https://www.renewable-ei.org/en/ activities/reports/img/ pdf/20180614/REI_ASG_ SecondReportSummary_EN.pdf.

[11] H. Huang. North-East Asia Energy Interconnection and Regional Development. Global Energy Interconnection Development and Cooperation Organization, Oct. 2018. Available at: https://www. unescap.org/sites/default/files/Session $\% 201-1 . \% 20$ GEIDCO.pdf

[12] Outlook on Power Interconnection in North-East Asia. China Electric Power Planning \& Engineering Institute (EPPEI), Oct. 2018. Available at: https:// www.unescap.org/sites/default/files/Session $\% 20$ 1-4.\%20China-EPPEI.pdf.

[13] S.V. Podkovalnikov, V.A. Savelev, O.V. Khamisov, L.Yu. Chudinova. Justification of Effectiveness of International Power Interconnections with Separation of Effects between Participants. Automation and Remote Control, Vol. 79, no. 10, pp. 1756-1765. 2018. DOI: $10.1134 / \mathrm{S} 0005117918100028$.

[14] O.V. Khamisov, S.V. Podkovalnikov. Shadow Price Analysis of Potential Northeast Asia Power System Interconnection, in Proc. of 2018 IEEE PES AsiaPacific Power and Energy Engineering Conference (APPEEC), Kota Kinabalu, Malaysia, pp. 606-610. IEEE, 2018.

[15] Projected Cost of Generating Electricity. International Energy Agency, Paris, 2015. Available at: https:// oecd-nea.org/ndd/pubs/2015/7057-proj-costselectricity-2015.

[16] IEEJ Outlook 2019 - Energy Transition and Thorny Path for $3 E$ Challenges. The Institute of Energy Economics, Japan, Tokyo, Oct. 2018. Available at: https://eneken.ieej.or.jp/data/8650.pdf.

[17] P.M.Mishra.AComparison ofDevelopment of Pumped Storage Hydropower in Europe and Asia. The Arctic University of Norway, Narvik, June, 2017. Available at: https://munin.uit.no/bitstream/handle/10037/12985/ thesis.pdf? sequence $=2 \&$ isAllowed $=y$.

[18] P. Luckow, E. Stanton, B. Biewald, S. Fields, S. Jackson, J. Fisher, R. Wilson, "Spring 2016 National Carbon Dioxide Price Forecast". Synapce Energy Economics, Inc., Cambridge, USA: Massachusetts. 2016. 38 p. Available at: http://www.synapse-energy. $\mathrm{com} / \mathrm{sites} / \mathrm{default} /$ files/2016-Synapse-CO2-PriceForecast-66-008.pdf.

[19] State and Trends of Carbon Pricing 2019. International Bank Reconstruction and Development / World Bank Group, Washington, USA, June 2019. 97 p. Available at: http://documents1.worldbank.org/ curated/en/191801559846379845/pdf/State-andTrends-of-Carbon-Pricing-2019.pdf. 


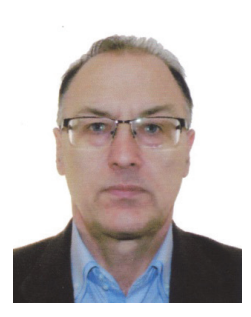

Sergei V. Podkovalnikov, Dr., is Head of the Department of Electric Power Systems at Melentiev Energy Systems Institute. His research interests are methods of decision-making in energy under uncertainty and multiple criteria, interstate electric ties and interconnected power systems, expansion planning of the electric power industry in a market environment. He is the author and coauthor of nearly 200 scientific papers and books.

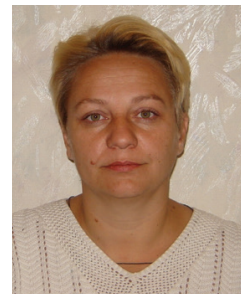

Lyudmila Yu. Chudinova is a Senior Researcher at Melentiev Energy Systems Institute. In 2005, she received a Ph.D. degree in the field of power system interconnections in Northeast Asia. Her scientific interests are interstate electric ties and hydropower. She published 40 scientific papers. 